\title{
TITANIUM POWDERS USED IN POWDER BED FUSION: THEIR RELEVANCE TO RESPIRATORY HEALTH
}

\author{
S. du Preez ${ }^{1 *}$, D.J. de Beer ${ }^{2} \&$ J.L. du Plessis ${ }^{1}$
}

\section{ARTICLE INFO}

Article details

Submitted by authors

Accepted for publication 19 Act 2018

Available online

10 Dec 2018

\section{Contact details \\ Corresponding author \\ dupreezsonette@nwu.ac.za \\ Author affiliations \\ 1 Occupational Hygiene and Health Research Initiative (OHHRI), North-West University Potchefstroom Campus, South Africa \\ 2 Department of Technology Transfer and Innovation Support North-West University Potchefstroom Campus, South Africa}

DOI

http://dx.doi.org/10.7166/29-4-1975
ABSTRACT

This study aimed to characterise three titanium powders used in powder bed fusion in terms of particle size, shape, and elemental composition for comparison with safety data sheet (SDS) information, and their relevance to additive manufacturing (AM) operators' respiratory health. Thoracic $(<10 \mu \mathrm{m})$ and respirable $(<4 \mu \mathrm{m})$ particles were present in the virgin and used powders. If inhaled, these particles have the potential to cause adverse health effects. Discrepancies in particle size and elemental composition compared with what was declared in the SDSs were found. The SDSs provided insufficient information, which places AM operators' health at risk. Recommendations for promoting AM operator health are provided.

\section{OPSOMMING}

Hierdie studie se doel was om titaanpoeiers wat tydens poeierlaagsamesmelting gebruik word te karakteriseer volgens partikel grootte, vorm, en materiaal element samestelling vir vergelyking met ' $n$ veiligheidsdatavel (VDV) en die relevansie daarvan op die respiratoriese gesondheid van die additiewe vervaardigingsoperateur. Torakale $(<10 \mu \mathrm{m})$ en respireerbare $(<4 \mu \mathrm{m})$ partikels was in nuwe en herbruikte poeiers teenwoordig, en indien ingeasem word kan dit tot ongewensde gesondheidseffekte lei. Teenstrydighede is in die partikel groottes en element samestelling teenoor wat in die VDV'e verklaar word, gevind. VDV'e verskaf nie genoegsame inligting nie, en hou dus 'n gesondheidsrisiko vir die operateur in. Aanbevelings vir die bevordering van die operateur se gesondheid word verskaf.

\section{INTRODUCTION}

Powder bed fusion (PBF) is described as the leading additive manufacturing (AM) technology for the production of three-dimensional metal structures [1]. PBF technologies make use of either a laser or an electron beam to melt and fuse metal powder particles together. The metals powders used include titanium, titanium alloys, and numerous stainless steel and other metal alloys. Titanium and its alloys are of importance and interest due to their broad application in the aerospace, medical, and automotive industries [2]. When other elements are alloyed with titanium, three classes of alloys form: alpha alloys, alpha-beta alloys, and beta alloys, each with their distinctive properties [3]. $\mathrm{Ti}_{6} \mathrm{Al}_{4} \mathrm{~V}$ is the most widely used titanium alloy; it consists of six per cent aluminium, four per cent vanadium, 0.3 per cent (maximum) iron, 0.2 per cent (maximum) oxygen, and the remainder titanium [4],[5].

Despite the fact that the build (processing) phase of $A M$ is an enclosed process, $A M$ (machine) operators may be exposed through inhalation to metal feedstock powders during the pre-processing and post-processing phases. Exposure can be either to virgin (new) powders (as provided by the powder manufacturer) or to used (recycled) powders. The pre-processing phase involves manual tasks such as vacuum cleaning of the AM machine build chamber to remove unmelted or unsintered 
powder, the handling of powder for size-selective powder sieving, and the loading of the powder into the $A M$ machine feedstock bins. The post-processing phase involves manual removal of the printed part(s) from the build chamber and manual removal of unmelted/-sintered powder, but may also include sanding, drilling, and sawing tasks to finish the product [6],[7].

To date, several studies have investigated the particle emissions from smaller desktop fused deposition modelling (FDM ${ }^{\top M}$ ) 3D printers using acrylonitrile butadiene styrene (ABS) and poly lactic acid (PLA) filaments; they found that these printers are high emitters of particulate matter [8-11]. Indoor air quality that declines during long build periods due to particle emissions [8] is of concern, due to its association with potentially adverse health effects [12-13]. Recently, a case of workrelated asthma was reported in an AM operator using FDM ${ }^{T M}$ printers with ABS filaments [14]. However, emission information for other $A M$ technologies is limited. Graff et al. [7] and Mellin et al. [15] reported the presence of submicron $(<1 \mu \mathrm{m})$ and $\sim 1-2 \mu \mathrm{m}$ particles that contained chromium, cobalt, and nickel during selective laser melting (SLM) from Inconel 939 alloy powder. Graff et al. [7] also reported the presence of smaller particle sizes in reused feedstock powders when compared with the virgin powders.

The size and chemical composition of AM powders is of importance when considering the respiratory health of $A M$ operators. Particle size determines whether particles are inhalable, and if inhalable, where they may be deposited in the respiratory tract [12],[16]. Particles can be classified into size fractions - inhalable, extrathoracic, thoracic, or respirable - depending on the regions of penetration. Inhalable particles $(<100 \mu \mathrm{m})(50 \%$ cutpoint) are inhaled through the nose and mouth and deposited in the nasopharyngeal region. Extrathoracic particles are inhaled, but do not penetrate beyond the larynx. Thoracic particles $(50 \%$ penetration of particles with an aerodynamic diameter of $10 \mu \mathrm{m})$ can penetrate beyond the larynx, while respirable particles ( $50 \%$ penetration of particles with an aerodynamic diameter of $4 \mu \mathrm{m}$ ) can penetrate the unciliated airways and be deposited in the alveolar region of the lungs [17-19]. The chemical composition of inhaled particles is important when investigating possible health effects [20]. Each metal constituent of AM powders potentially poses a different respiratory health hazard. Titanium and iron inhalation may lead to respiratory irritation, including coughing and sneezing, while long-term inhalation of aluminium dust may lead to pulmonary fibrosis [21-23].

The purpose of a safety data sheet (SDS) is to provide information on chemical safety, potential hazards (health, fire, reactivity, and environmental), and safe work practices for a specific chemical product. It serves as an essential starting point for the development of a complete health and safety programme in the workplace [24]. SDSs, which are provided with substances hazardous to health, are fundamental in evaluating the health and safety of a workplace [25]. Slotwinski and Garboczi [26] and Graff et al. [7] indicated that, in most cases, AM powder suppliers only declare a particle size range for virgin powders. Limited information is provided in these SDSs, and there are no safe operating guidelines in user manuals, which could provide a false sense of protection of the AM operator's health [27], while in reality a risk to health may exist.

The aim of this study was to establish the particle size distribution (PSD), shape, and elemental composition of titanium powders obtained from three AM facilities located in South Africa in order to compare them with the corresponding information declared in the SDSs of these powders. The relevance of any potential discrepancies or shortcomings in SDS information to AM operators' respiratory health was explained, and recommendations are provided to both AM powder manufacturers/suppliers and the end users.

\section{MATERIALS AND METHODS}

Samples of virgin and used (recycled) titanium powders and their respective SDSs were collected from three AM facilities in South Africa that use PBF. Samples were placed into separate storage vials for analysis. Particle size was evaluated using particle size distribution (PSD) and static image analysis (scanning electron microscopy [SEM]). Particle shape was evaluated through static image analysis of dry dispersed powders. X-ray diffraction (XRD) analysis was conducted to determine the elemental composition of the powders.

\subsection{Particle size, shape evaluation, and analysis}

PSD analysis by laser diffraction was conducted using a Malvern Mastersizer 2000 particle size analyser and its associated software (Malvern Instruments Ltd, United Kingdom). Virgin and used 
powder samples were analysed individually by mixing them with a dispersing agent $(1 \mathrm{ml}$ of $99.9 \%$ pure ethanol). Prior to each measurement, a background measurement was performed. After completion of the background measurement, a sufficient quantity of the raw powder was added to render an obscuration of 10 to 20 per cent, whereafter the particle size measurement was made. All samples were analysed in triplicate.

Particle shape evaluation was conducted using the Malvern Morphologi G3 with its associated software (Malvern Instruments Ltd, United Kingdom). Each powder sample $\left(5 \mathrm{~mm}^{3}\right)$ was placed in the instrument's sample dispersion unit. After powder dispersion, images of individual particles were captured and analysed by automatic microscopic scanning. All samples were analysed in triplicate.

SEM analysis was conducted by placing about three to five $\mathrm{mm}^{3}$ of powder on double-sided adhesive carbon strips and preparing the samples for the observation of their surface topography, by coating them with an SPI Module sputter coater (SPI-Module ${ }^{T M}$. Sputter Coater, SPI Supplies, USA) fitted with a gold palladium source. Samples were studied using a Phenom pro-desktop SEM (Phenom PRO Desktop SEM, Phenom-World B., The Netherlands) at a power of five kV at magnifications enabling visualisation of particles $100 \mu \mathrm{m}$ and $<10 \mu \mathrm{m}$ in size.

\subsection{Elemental composition analysis}

XRD analysis was conducted on powder samples using a powder diffractometer (X'Pert Pro XRD, PANalytical, The Netherlands). The preparation method involved finely pulverising the powder and placing the undiluted powder samples, using a back-loading technique, on to a spinner stage inside the XRD. The samples were then scanned using X-rays generated by a Cu X-Ray tube (PW3376/00 Co LFF tube, PANalytical, The Netherlands).

\subsection{Statistical analysis of data}

PSD and the shape of virgin and used powders were compared with unpaired t-tests (Graphpad Prism, version 7, Graphpad Software Inc., USA). All p values $\leq 0.05$ were considered statistically significant.

\section{RESULTS}

The particle sizes of three titanium powders were compared with those declared in the representative powders' SDSs. The PSD from Facility A's virgin Titanium 64 (Ti64) powder was in accordance with the SDS, with no particle size measuring greater than $50 \mu \mathrm{m}$ (Table 1). Ten per cent of the virgin particles were $<11.11 \pm 0.69 \mu \mathrm{m}$. Facility B's powder SDS showed that the $\mathrm{Ti}_{6} \mathrm{AlV}_{4}$ virgin powder should contain particles in a size range of 25 to $45 \mu \mathrm{m}$; however, 10 per cent of the particles were smaller than $25.78 \pm 0.59 \mu \mathrm{m}$, and particles larger than $45 \mu \mathrm{m}[\mathrm{d}(0.9)=67.37 \pm 2.70 \mu \mathrm{m}]$ were also found. The SDS of Facility C's powder did not state any particle size for the CL41Ti EL (titanium alloy / $\mathrm{Ti}_{6} \mathrm{AlV}_{4}$ ) powder. The measured particle size results for the CL41Ti EL powder showed that 10 per cent of the particles were smaller than $16.57 \pm 0.44 \mu \mathrm{m}$ for virgin powders, and 10 per cent were smaller than $20.96 \pm 1.04 \mu \mathrm{m}$ for used powders. In $A M$, powders are often recycled and reused. No significant differences were found in the PSD of the virgin and used powders, with the exception of CL41Ti EL powder; in this powder, the $d(0.1)$ - i.e., the mean size of 10 per cent of particles - was significantly higher, and the $d(0.9)$ was significantly lower for the used powder. From SEM images, thoracic $(<10 \mu \mathrm{m})$ and respirable $(<4 \mu \mathrm{m})$ particles were observed in powders from all three facilities (Figure 1). Static image shape analysis showed that powder particles from all three facilities were spherical in shape with smooth surfaces. No significant changes in particle circularity and edge roughness (convexity) were evident between the virgin and used powders.

The elemental composition analysis (XRD analysis) of all three powders differed from the composition stated in the respective SDSs. The titanium percentages in the Ti64 powder (Facility A) and the CL41Ti EL powder (Facility C) were slightly higher - 2.6 per cent and 5.1 per cent respectively - than those stated in the SDSs. For $\mathrm{Ti}_{6} \mathrm{AlV}_{4}$ (Facility B), only the aluminium percentage was listed in the SDS. The aluminium and vanadium composition also differed from the reported SDS composition for all three powders. Rutile is a common form of titanium dioxide $\left(\mathrm{TiO}_{2}\right)$ [4] and was identified in the CL41Ti EL powder (Facility C), although it was not listed in the SDS. XRD analysis also revealed differences in elemental composition between the virgin and used Ti64 and CL $41 \mathrm{Ti}$ EL powders. 
Table 1: SDS information, PSD, particle shape, and SEM analysis of virgin and used titanium powders. Data reported as mean \pm standard deviation

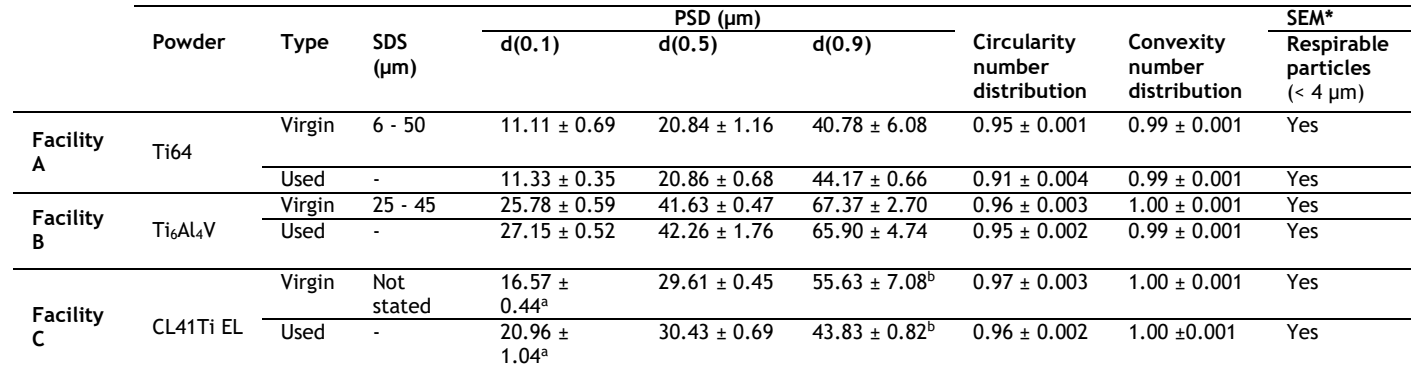

\section{Legend:}

- $\quad d(0.1) 10$ per cent of the particles are smaller than the stated diameter; $d(0.5) 50$ per cent of the particles are smaller than the stated diameter; $\mathrm{d}(0.9) 90$ per cent of the particles are smaller than the stated diameter.

Not indicated in SDS.

- $\quad$ a-b Statistically significant differences $(p \leq 0.05)$.

- Circularity: The ratio of the perimeter of a circle with the same area as the particle, divided by the perimeter of the actual particle image.

- $\quad$ Convexity: Measurement of the edge roughness of a particle.

- $\quad$ *Based on visual evaluation of SEM images.

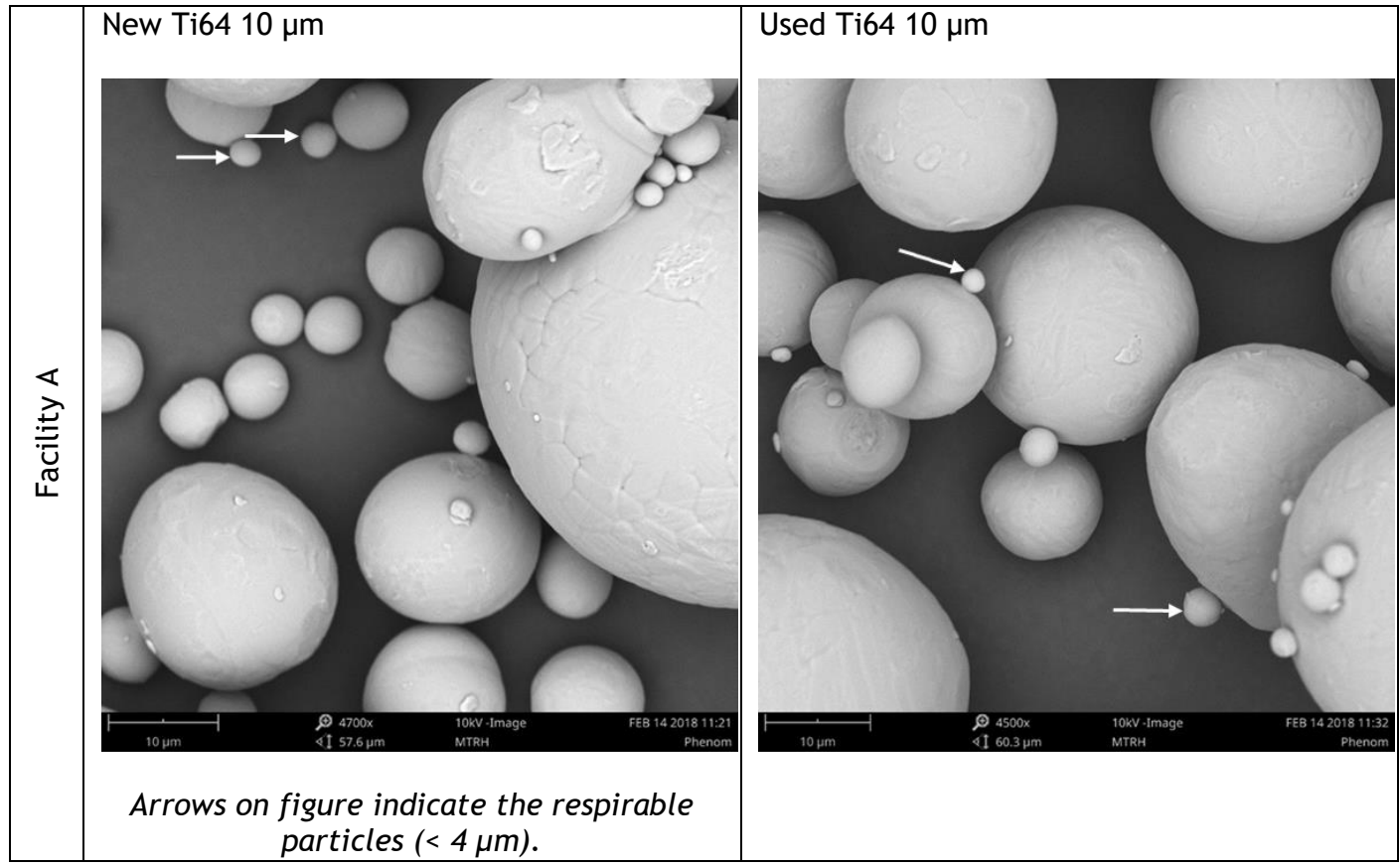

Figure 1a: SEM images from virgin and used titanium powders from Facilities A, B, and C on a $10 \mu \mathrm{m}$ scale showing the presence of respirable particles. 


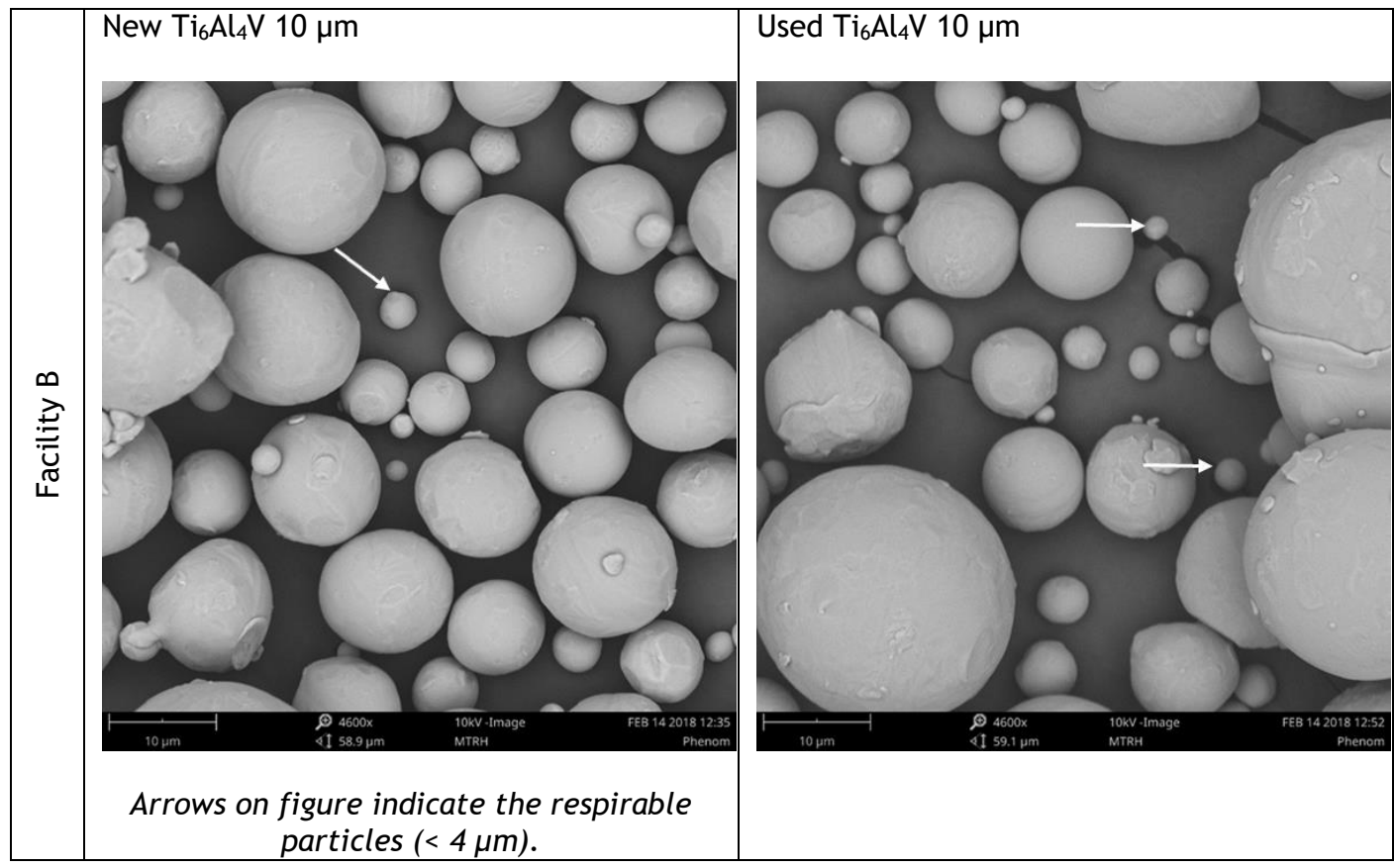

Figure 1b: SEM images from virgin and used titanium powders from Facilities $A, B$, and $C$ on a $10 \mu \mathrm{m}$ scale showing the presence of respirable particles.

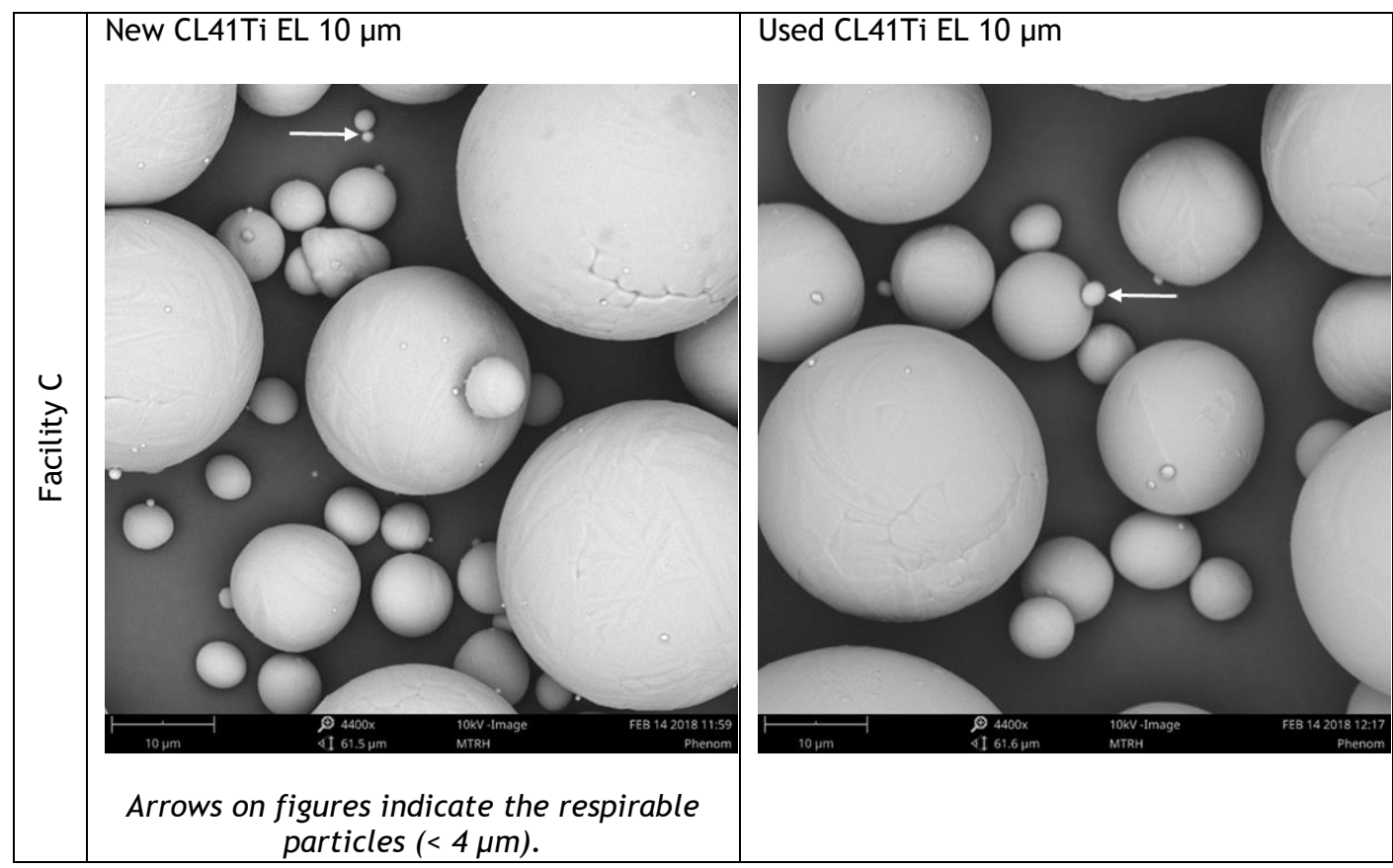

Figure 1c: SEM images from virgin and used titanium powders from Facilities $A, B$, and $C$ on a $10 \mu \mathrm{m}$ scale showing the presence of respirable particles. 
Table 2: Elemental composition of virgin and used titanium powders

\begin{tabular}{|c|c|c|c|c|c|c|c|c|}
\hline \multirow[b]{2}{*}{ Facility } & \multirow[b]{2}{*}{ Powder } & \multirow[b]{2}{*}{ Sample } & \multirow[b]{2}{*}{ SDS/XRD } & \multicolumn{5}{|c|}{ Elemental composition (\%) } \\
\hline & & & & Titanium (Ti) & $\begin{array}{l}\text { Aluminium } \\
\text { (Al) }\end{array}$ & $\begin{array}{l}\text { Vanadium } \\
\text { (V) }\end{array}$ & $\begin{array}{l}\text { Iron } \\
(\mathrm{Fe}) \\
\end{array}$ & Rutile \\
\hline \multirow{3}{*}{ A } & \multirow{3}{*}{ Ti64 } & \multirow[t]{2}{*}{ Virgin } & SDS $^{\mathrm{a}}$ & $89.00-90.00$ & $5.50-6.75$ & $3.50-4.50$ & $\begin{array}{l}<3000 \\
\text { ppm }\end{array}$ & \\
\hline & & & XRD & 92.60 & $7.40^{\mathrm{b}}$ & & & \\
\hline & & Used & XRD & 86.00 & $14.00^{\mathrm{b}}$ & & & \\
\hline \multirow{3}{*}{ B } & \multirow{3}{*}{$\mathrm{Ti}_{6} \mathrm{Al}_{4} \mathrm{~V}$} & \multirow{2}{*}{ Virgin } & SDS $^{\mathrm{C}}$ & - & $5.00-10.00$ & - & & \\
\hline & & & XRD & 93.9 & 4.5 & 1.6 & & \\
\hline & & Used & XRD & 94.2 & 4.3 & 1.5 & & \\
\hline \multirow{3}{*}{ C } & \multirow{3}{*}{$\begin{array}{l}\text { CL41Ti } \\
\text { EL }\end{array}$} & \multirow{2}{*}{ Virgin } & SDS $^{d}$ & $88.40-90.40$ & $5.50-6.50$ & $3.50-4.50$ & $0-0.25$ & \\
\hline & & & XRD & 95.50 & $4.30^{\mathrm{b}}$ & & & 0.20 \\
\hline & & Used & XRD & 95.10 & $4.90^{\mathrm{b}}$ & & & \\
\hline
\end{tabular}

aSDS also report $\mathrm{O}<2000 \mathrm{ppm}, \mathrm{N}<500 \mathrm{ppm}, \mathrm{C}<800 \mathrm{ppm}, \mathrm{H}<150 \mathrm{ppm}$; ${ }^{\mathrm{b} X R D}$ analysis reported AlV; ${ }^{\mathrm{C}} \mathrm{Only}$ Al is listed in the SDS; dSDS also report C $0-0.08 \%, 00-0.13 \%, \mathrm{~N} 0-0.05 \%, \mathrm{H} 0-0.012 \%$. Rutile is the most common form of titanium dioxide $\left(\mathrm{TiO}_{2}\right)$ [4].

\section{DISCUSSION}

There is limited knowledge about emissions and exposure for $A M$ process categories other than material extrusion (FDM $\left.{ }^{\top M}\right)$. To date, only two studies have shown that particles containing metals are emitted from PBF (selective laser melting) when using a nickel-based Inconel 939 powder [7],[15]. Mellin et al. [15] also emphasised that the SDSs provided by the manufacturer/supplier of this powder disclosed minimal information on the size of the powder particles. To address this knowledge gap, we compared the particle size and chemical composition of PBF titanium powders as declared in the SDSs with that obtained from our own evaluation of particle size, shape, and elemental composition.

PSD analysis of virgin powders showed particle size conformance to that stated in the SDS for only one of the three powders included in this study (Facility A, Ti64). For the virgin $\mathrm{Ti}_{6} \mathrm{Al}_{4} \mathrm{~V}$ powder, 10 per cent of the powder particles were equal to or smaller [ $d(0.1)=25.78 \pm 0.59 \mu \mathrm{m}$ ] than the minimum particle size $(25 \mu \mathrm{m})$ stated in the SDS, while the SDS stated no particle size for the CL41Ti EL powder (Facility C). The SDS conformance of one of the powders used in this study (Ti64) is in agreement with the finding of Graff et al. [7], who stated that the virgin powder particle size of an Inconel 939 powder corresponded to the size disclosed by the manufacturer. However, the presence of smaller particles in the $\mathrm{Ti}_{6} \mathrm{Al}_{4} \mathrm{~V}$ powder, and the non-disclosure of particle size of the CL41Ti EL powder, confirmed that there were shortcomings in the respective SDSs. Recycled/reused powder particle sizes $[d(0.1), d(0.5), d(0.9)]$ were similar to the virgin powder particle sizes, except for the CL41Ti EL powder, where the virgin powder particles were statistically $(p \leq 0.05)$ significantly smaller than those of the recycled/reused powder $[\mathrm{d}(0.1)]$. Our findings are supported by Graff et al. [7], who reported that used Inconel 939 powder particle sizes corresponded to those of the virgin powder (15 to $45 \mu \mathrm{m})$, and by Mellin et al. [15], who found spherical smaller particles, one to five $\mu \mathrm{m}$ in size, in the recycled Inconel 939 powder. Mellin et al. [15] argued that these smaller particles are satellites, formed during powder manufacturing, that detach from larger particles during the handling, shearing, or heating of the powder.

Particles of all three powders (virgin and reused) are considered to be inhalable (Ti64 > $\left.\mathrm{Ti}_{6} \mathrm{Al}_{4} \mathrm{~V}>\mathrm{CL} 41 \mathrm{Ti} E L\right)$, with an estimated 9.1 per cent of inhaled Ti64 particles $[\mathrm{d}(0.5)=20.84 \pm 1.16 \mu \mathrm{m}]$ able to penetrate beyond the larynx, and almost 0.9 per cent $[\mathrm{d}(0.1)=11.11 \pm 0.69 \mu \mathrm{m}]$ able to reach the unciliated airways [17]. Static image shape analysis and SEM images showed the presence of spherical, smooth-surfaced respirable powder particles $<4 \mu \mathrm{m}$ in all three powders (virgin and reused), thus supporting the finding and explanation for their presence [15]. From a health perspective, it is estimated that 99.6 per cent of all inspired $4 \mu \mathrm{m}$ sized particles will penetrate beyond the larynx, with 55.9 per cent of these particles reaching the unciliated airways [17]. These respirable particles, therefore, penetrate deep into the lungs; may not be easily removed/cleared from the respiratory system; and may be absorbed or elicit toxic effects [12],[18],[28]. Regardless of composition, their repeated inhalation over a long period of time is, in all likelihood, hazardous [15]. 
Elemental composition analysis of virgin powders differed from the composition disclosed in the SDSs. For all three powders, our analysis found slightly more titanium, and consequentially less aluminium and vanadium (Table 2), than stated in the SDSs that were provided. Rutile, the most common form of titanium dioxide $\left(\mathrm{TiO}_{2}\right)$ in titanium ore [4],[29], was present in the CL41Ti EL powder, while we did not detect any iron. Our findings again confirm that there are shortcomings in the information in SDSs provided by powder manufacturers. Used powder properties may change in the $A M$ build chamber environment due to repeated (recycled) use [30], and our analysis found less titanium present in the used Ti64 powder than in the virgin powder.

Titanium alloy AM powders contain several metals, such as titanium, iron, aluminium, and vanadium that present a potential risk to health when inhaled. There is a lack of epidemiological studies on the health effects of titanium. However, titanium exposure, along with co-exposure to other metals, may cause an impaired immune response and cytokine release [31]. Titanium is highly reactive and, in the presence of oxygen, leads to the formation of $\mathrm{TiO}_{2}$. Although $\mathrm{TiO}_{2}$ is toxicologically inert (with the exception of nano-sized $\left.(<100 \mathrm{~nm}) \mathrm{TiO}_{2}\right)$, it is considered to be a nuisance particulate [32]. Nuisance particulates are defined as airborne materials that have little harmful effect on the lungs, but leave deposits in eyes, ears, and nasal passages, and may adversely affect one's vision' [24],[33].

Iron serves as a beta alloying element in titanium metal powders, adding to the strength and fabricability of these alloys [3]. Inhalation of iron dust may lead to respiratory irritation, and aluminium dust can possibly cause pulmonary fibrosis [21-23]. Vanadium is a trace element, and adverse respiratory effects such as coughing, wheezing, and sore throats could be observed in workers exposed to vanadium compounds [35-36]. In a study by Li et al. [36], it was also reported that exposure to vanadium compounds can cause neuro- and renal toxicity, and they demonstrated an association between vanadium exposure and altered neurobehavioral function [36].

To summarise, AM PBF powders investigated in this study are inhalable, containing thoracic and respirable sized particles with the potential to deposit beyond the larynx and alveoli if inhaled. The elemental composition suggests the potential risk of respiratory health effects; therefore, AM operators handling powders should be informed about the health risks of the powders with which they work, and proper control measures should be in place to reduce and/or eliminate respiratory exposure. Further studies assess emissions during PBF and the personal exposure of AM operators during titanium metal powder handling and processing tasks.

Our finding is that the majority of SDSs of metal AM powders have shortcomings when disclosing particle size and elemental composition. A SDS is an essential, legally required document provided by a manufacturer/supplier of, in this case, the $A M$ metal powder used in an occupational setting [24],[37]. SDSs are intended to be a primary health and safety resource for employers and employees, and should provide information about chemical safety, potential hazards (health, fire, reactivity, and environmental), and safe work procedures (handling and storage) for a specific substance [24]. A correct and comprehensive SDS should contribute toward effective decisionmaking for employee health and wellbeing, starting with initial health risk assessments and, consequently, appropriate control measures by the employer, aimed at reducing and/or eliminating exposure to the specified substance. Occupational health and safety legislation, in this case the South African Occupational Health and Safety Act (Act 85 of 1993), requires manufacturers to ensure that the supplied substance, if properly used, is safe and poses no risk to the health of the person using it (Section 10) [38]. If, however, a safety or health risk exists, the manufacturer/supplier should ensure that information is available about the risk to health and safety associated with the substance [38]. This will enable the employer to assess the risk, but also to reduce or eliminate the risk (Section 8). Our particle size and elemental composition findings, differed in most instances from the SDSs, which provide insufficient information to the employer and the AM operator about the powder composition and each element's potential health risks; and this is therefore a matter of concern. Findings from this study suggest that there are circumstances in which the inaccurate/incomplete SDS could create a false sense of protection about the AM operators' health. It is therefore recommended that manufacturers provide accurate and comprehensive information in SDSs on, in particular, the particle size and elemental composition of the AM powders. The AM operator should be able to refer to the SDS as a guide for safe powder handling, and should be informed of the potential health risks involved. Of equal importance is that, if an employer or an AM operator identifies an incomplete SDS, then characterisation of the powder in terms of particle size and elemental composition can be done before it is used. 
Regulation 3 of the South African Hazardous Chemical Substances (HCS) Regulations (1995) states that an employer should ensure that where a worker - in this case, the AM operator - may be exposed to hazardous chemical substances (i.e., AM powders), he/she receives adequate training. According to Regulation 4 of these regulations, the worker (AM operator) also has a responsibility to obey instructions from the employer in preventing release and consequential exposure to substances, wear the correct personal protective equipment, maintain proper housekeeping procedures in the workplace, and follow the information and training provided by the employer.

\section{CONCLUSION}

This study investigated three different $A M$ titanium alloy powders (virgin and used), together with their relevant SDSs, and analysed the powders in terms of particle size, shape, and elemental composition. Thoracic $(<10 \mu \mathrm{m})$ and respirable $(<4 \mu \mathrm{m})$ metal-containing particles were present in the virgin and used powders. If inhaled, these metal-containing particles have the potential to cause adverse health effects. From the results, only a small percentage of particles are able to penetrate beyond the larynx. Although short-term health effects may not be immediately experienced by AM operators, repeated inhalation over a long period of time may be hazardous. Discrepancies in particle size and elemental composition to what was declared in the SDSs were found. This study creates a better understanding of virgin and used titanium powders to which AM operators in PBF are exposed, and highlights the shortcomings in SDS information. Recommendations, in line with occupational health and safety legislation, are provided to assist and guide manufacturers, employers, and AM operators in promoting AM operators' health.

\section{ACKNOWLEDGMENTS}

This work was funded by the South African Department of Science and Technology, and forms part of the Collaborative Program for Additive Manufacturing, Qualification of Additive Manufacturing of Ti6Al4V for Medical Implants and Aerospace Components.

\section{REFERENCES}

[1] Matthews, M.J., Guss, G., Khairallah, S.A., Rubenchik, A.M., Depond, P.J. and King, W.E. 2016. Denudation of metal powder layers in laser powder bed fusion processes, Acta Materialia, 114, pp. 3342.

[2] Dutta, B. and Froes, F.H. 2014. Additive manufacturing of titanium alloys. Advanced materials \& processes, Advanced Materials Research, 1019, pp. 19-25.

[3] Froes, F.H. 2015. Titanium: Physical metallurgy, processing, and applications, $1^{\text {st }}$ edition. Ohio: ASM International.

[4] Donachie, M.J. 2000. Titanium: A technical guide, $2^{\text {nd }}$ edition. Ohio: ASM International.

[5] Gibson, I., Rosen, D.W. and Stucker, B. 2015. Additive manufacturing technologies, $2^{\text {nd }}$ edition. New York: Springer.

[6] Deak, S. 1999. Safe work practices for rapid prototyping, Rapid Prototyping Journal, 5(4), pp. 161-163.

[7] Graff, P., Ståhlbom, B., Nordenberg, E., Graichen, A., Johansson, P. and Karlsson, H. 2016. Evaluating measuring techniques for occupational exposure during additive manufacturing of metals, Journal of Industrial Ecology, 11(60), pp. 1-18.

[8] Afshar-Mohajer, N., Wu, C.Y. and Ladun, T. 2015. Characterization of particulate matters and total VOC emissions from a binder jetting 3D printer, Building and Environment, 93(2), pp. 293-301.

[9] Kim, Y., Yoon, C., Ham, S., Park, J., Kim, S., Kwon, O. and Tsai, P.J. 2015. Emissions of nanoparticles and gaseous material from 3D printer operation, Journal of Environmental Science and Technology, 49, pp. 12044-12503.

[10] Deng, Y., Cao, S., Chen, A. and Guo, Y. 2016. The impact of manufacturing parameters on submicron particle emissions from a desktop 3D printer in the perspective of emission reduction, Building and Environment, 11(60), pp. 1-18.

[11] Floyd, E.L., Wang, Y. and Regens, J.L. 2017. Fume emissions from a low-cost 3-D printer with various filaments, Journal of Occupational and Environmental Hygiene, 11(60), pp. 1-18.

[12] Maynard, A.D. and Kuempel, E.D. 2005. Airborne nanostructured particles and occupational health, Journal of Nanoparticle Research, 7, pp. 587-614.

[13] Stabile, L., Scungio, M., G. Buonanno, G., Arpino, F. and Ficco, G. 2016. Airborne particle emission of a commercial 3D printer: The effect of filament material and printing temperature, Indoor Air, 11(60), pp. $1-18$.

[14] House, R., Rajaram, N. and Tarlo, S.M. 2017. Case report of asthma associated with 3D printing, Occupational Medicine, 67(8), pp. 652-654. 
[15] Mellin, P., Jonsson, C., Åkermo M., Fernberg, P., Nordenberg, E., Brodin, H. and Strondl, A. 2016. Nano-sized by-products from metal 3D printing, composite manufacturing and fabric production, Journal of Cleaner Production, 139, pp. 1224- 1233.

[16] Stephens, B., Azimi, P., Orch, Z. E. and Ramos, T. 2013. Ultrafine particle emissions from desktop 3D printers, Atmospheric Environment, 79, pp. 334-339.

[17] CEN. 1993. European Committee for Standardization. Workplace atmospheres: Size fraction definitions for measurement of airborne particles (Report No. BS EN 481:1993). London, England: CEN, British Standards Institute.

[18] Brown, J.S., Gordon, T., Price, O. and Asgharian, B. 2013. Thoracic and respirable particle definitions for human health risk assessment, Particle Fibre Toxicology Journal, 10, pp. 1-12.

[19] Notø, H.P., Nordby K.C. and Eduard, W. 2016. Relationships between personal measurements of 'total' dust, respirable, thoracic, and inhalable aerosol fractions in the cement production industry, Annals of Occupational Hygiene, 60(4), pp. 453-466.

[20] Happo, M.S., Sippula, O., Jalava, P., Rintala, H., Leskinen A., Komppula, M., Kuuspalo, K., Mikkonen, S., Lehtinen, K., Jokiniemi, J. and Hirvonen, M.R. 2014. Role of microbial and chemical composition in toxicological properties of indoor and outdoor air particulate matter, Particle and Fibre Toxicology, 11(60), pp 1-18.

[21] Adams, S. 2006. Allergies in the workplace, Current Allergy \& Clinical Immunology, 19(2), pp. 82-86.

[22] Rossbach, B., Buchta, M., Csanády, G.A., Filser, J.G., Hilla, W., Windorfer, K., Stork, J., Zschiesche, W., Gefeller, O., Pfahlberg, A., Schaller, K.H., Egerer, E., Pinzón, L.C.E. and Letzel, S. 2006. Biological monitoring of welders exposed to aluminium, Toxicology Letters, 162(2-3), pp. 239-245.

[23] Tokar, E.J., Boyd, W.A., Freedman, J.H. and Waalkes, M.P. 2013. Casarett \& Doull's toxicology. New York: McGraw-Hill.

[24] Canadian Centre for Occupational Health and Safety (CCOHS). 2016. Welding: Fumes and gases. Available at: https://www.ccohs.ca/oshanswers/safety_haz/welding/fumes.html. [Accessed: 7 February 2018].

[25] Bernstein, J.A. 2002. Material safety data sheets: Are they reliable in identifying human hazards? Journal of Allergy and Clinical Immunology, 11(60), pp 1-18.

[26] Slotwinski, J.A. and Garboczi, E.J. 2015. Metrology needs for metal additive manufacturing powders, The Journal of The Minerals, Metals \& Materials Society (TMS) 67(3), pp. 538-543.

[27] Short, D., Sirinterlikci, A., Badger, P. and Artieri, B. 2015. Environmental, health, and safety issues in rapid prototyping, Rapid Prototyping Journal, 21, pp. 105-110.

[28] Oberdörster, G., Oberdörster, E. and Oberdörster, J. 2005. Nanotoxicology: An emerging discipline evolving from studies of ultrafine particles. Environmental Health Perspective, 113(7), pp. 823-839.

[29] Dutta, B. and Froes, F.H. 2017. The additive manufacturing (AM) of titanium alloys, Metal Powder Report, 72(2), pp. 96-106.

[30] Cooke, A. and Slotwinski, J. 2012. Properties of metal powders for additive manufacturing: A review of the state of the art of metal powder property testing, National Institute of Standards and Technology IR 7873, 11(60), pp. 1-18.

[31] Jin, T. and Berlin, M. 2015. Handbook on the toxicology of metals. $4^{\text {th }}$ edition. USA, Elsevier.

[32] Liu, J., Goyer, R.A. and Waalkes, M.P. 2008. Casarett \& Doull's toxicology. New York: McGraw-Hill.

[33] Cherrie, J.W., Brosseau, L.M., Hay, A. and Donaldson, K. 2013. Low-toxicity dusts: Current exposure guidelines are not sufficiently protective, Annals of Occupational Hygiene, (57)6, pp. 685-691.

[34] Crans, D.C., Smee, J.J., Gaidamauskas, E. and Yang, L. 2004. The chemistry and biochemistry of vanadium and the biological activities exerted by vanadium compounds, Chemical Review, 104(2), pp. 849902.

[35] Assem, F. and Oskarson, A. 2015. Handbook on the toxicology of metals. $4^{\text {th }}$ edition. USA, Elsevier.

[36] Li, H., Zhou, D., Zhang, Q., Feng, Q., Zheng, W., He., K. and Lan, Y. 2013. Vanadium exposure-induced neurobehavioral alterations among Chinese workers, Neurotoxicology, 36, pp. 49-54.

[37] Department of Labour (DOL). 1995. Hazardous chemical substances regulations, 1995. http://www.acts.co.za/occupational-health-and-safety-act-1993/index.html [Accesssed: 9 Febrauary 2018].

[38] Department of Labour (DOL). 1993. Occupational Health and Safety Act no. 85 of 1993. http://www.acts.co.za/occupational-health-and-safety-act-1993/index.html [Accesssed: 9 Febraury 2018]. 